\title{
Heat transfer in fluidized and fixed beds of adsorption chillers
}

\author{
Jaroslaw Krzywanski ${ }^{1,}{ }^{*}$, Karolina Grabowska ${ }^{1}$, Marcin Sosnowski ${ }^{1}$, Anna Zylka ${ }^{1}$, Anna Kulakowska $^{1}$, Tomasz Czakiert $^{2}$, \\ Karol Sztekler ${ }^{3}$, Marta Wesolowska ${ }^{3}$ and Wojciech Nowak $^{3}$ \\ ${ }^{1}$ Jan Dlugosz University in Czestochowa, Faculty of Science and Technology A. Krajowej 13/15, 42-200 Czestochowa, Poland \\ ${ }^{2}$ Czestochowa University of Technology, Institute of Advanced Energy Technologies, Dabrowskiego 73, 42-200 Czestochowa, Poland \\ ${ }^{2}$ AGH University of Science and Technology, Faculty of Energy and Fuels, A. Mickiewicza 30, 30-059 Cracow, Poland
}

\begin{abstract}
An innovative idea, shown in the paper constitutes in the use of the fluidized bed of sorbent, instead of the conventional, fixed-bed, commonly used in the adsorption chillers. Bed-to-wall heat transfer coefficients for fixed and fluidized beds of adsorbent are determined. Sorbent particles diameters and velocities of fluidizing gas are discussed in the study. The calculations confirmed, that the bed-to-wall heat transfer coefficient in the fluidized bed of adsorbent is much higher than that in a conventional bed..
\end{abstract}

\section{Nomenclature}

c constant representing the mixing of gas in the vicinity of wall, -

$\mathrm{C}$ specific heat capacity, $\mathrm{J} \mathrm{kg}^{-1} \mathrm{~K}^{-1}$

$\mathrm{U}$ heat transfer coefficient, $\mathrm{W} \mathrm{m}^{-2} \mathrm{~K}_{-1}$

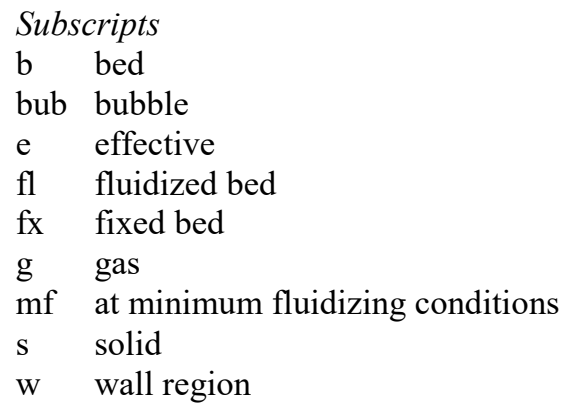

Superscripts

0 for stagnant gas conditions

\section{Greek Symbols}

$\delta$ fraction of bed in bubbles, -

$\varepsilon \quad$ void fraction in a bed at minimum fluidizing conditions, -

$\lambda$ thermal conductivity, $\mathrm{W} \mathrm{m}^{-1} \mathrm{~K}^{-1}$

$\rho$ density, $\mathrm{kg} \mathrm{m}^{-3}$

$v_{b} \quad$ velocity of a bubble rising through a bed, $\mathrm{m}^{\mathrm{s}-1}$

$v_{0} \quad$ superficial gas velocity, $\mathrm{m} \mathrm{s}^{-1}$

\section{Acronyms}

AC Adsorption Chiller

\section{Introduction}

The main disadvantages of conventional fixed-bed adsorption chillers are low coefficients of performance (COP) [1-4].

One of the well-known method, allowing to improve the heat transfer coefficient between the bed and the immersed heating surface, widely used in energy boilers, is using fluidized bed [5-15]. A similar idea appears concerning to adsorption chillers $[1,2,16]$. Wang et al. [17] proposed to use a fluidized - bed adsorber/desorber for the adsorption refrigeration system. The authors pointed out that the fluidized adsorbent can enhance the heat and mass transfer, leading to the increase the specific cooling power.

A periodic operating silica gel fluidized bed unit to adsorb/desorb moisture in air-conditioning systems was proposed by Chen et al. [18] The authors reported possibility to increase the adsorption and desorption processes in that the fluidized bed system compared with the unit equipped with a packed bed.

An inclined-fluidized bed in the adsorption and desorption operations was carried out by Hamed [19]. Rogala et al. considered air-fluidized systems developing a method for the prediction of silica gel-water adsorption [20].

The objective of the paper is to study the wall-to-bed heat transfer coefficient in fluidized and fixed beds of adsorption chillers.

\footnotetext{
"Corresponding author: j.krzywanski@ujd.edu.pl
} 


\section{Material and methods}

The re-heat two-stage adsorption chiller (AC) was considered in the study. This AC comprises of four adsorbent beds, evaporator, and condenser [21,22]. Silica gel and water stand for a working pair. The scheme of the adsorption chiller is shown in Fig. 1.

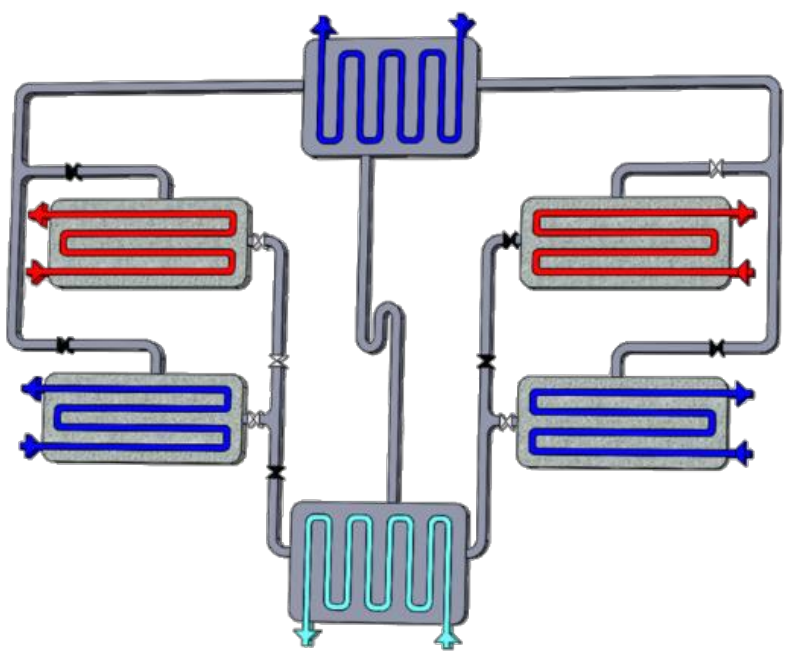

Fig. 1. The re-heat two-stage adsorption chiller.

The operational parameters of the chiller in standard operating conditions are as follows: flow rates of hot and cooling water in the adsorber: $0.5 \mathrm{~kg} \mathrm{~s}^{-1}$, temperatures of cooling and chilled water: $30{ }^{\circ} \mathrm{C}$ and $14{ }^{\circ} \mathrm{C}$, respectively. Further details of the chiller can be found elsewhere $[21,22]$. Three different materials are considered during the study: silica-gel, zeolite, and carbon nanotubes.

According to Kunii and Levenspiel (1991) a heat transfer coefficient for the wall region with flowing gas and the fixed bed can be described as follows:

$$
\begin{gathered}
U_{f x}=U_{w}^{0}+c_{w}\left(C_{g} \rho_{g} v_{0}\right)= \\
=\frac{2 \lambda_{e w}^{0}}{d_{p}}+c_{w}\left(C_{g} \rho_{g} v_{0}\right)
\end{gathered}
$$

where: $\mathrm{c}_{\mathrm{w}}=0.05$.

The heat transfer coefficient between the heat exchanger surface and a fluidized bed can be written, as follows [23]:

$$
U_{f l}=\frac{1-\delta}{\frac{1}{U_{f x}}+1.13\left[\lambda_{e}^{0} \rho_{s}\left(1-\varepsilon_{m f}\right) C_{s} n_{w} /\left(1-\delta_{w}\right)\right]^{0.5}}
$$

where:

$$
\begin{aligned}
& \delta=\frac{v_{0}-v_{m f}}{v_{b}-v_{m f}}, \\
& v_{b}=0.711\left(g d_{b u b}\right)^{0.5}
\end{aligned}
$$

Taking into account the above equations, we can assess heat transfer coefficients in the wall region of fixed and fluidized bed with flowing gas, i.e. water vapor as an adsorbate, $\mathrm{U}_{\mathrm{fx}}$, and $\mathrm{U}_{\mathrm{fl}}$, respectively.

\section{Results and discussion}

The influence of superficial gas velocity on heat transfer for fixed and fluidized bed of silica gel, zeolite, and carbon nanotubes are given in Table 1 .

The obtained results reveal, that the bed-to-wall heat transfer coefficient during fluidization is much higher than the one for a fixed bed.

The influence of superficial gas velocity on bed-towall heat transfer coefficient for different shares of carbon nanotubes in the bed of silica gel particles is given in Table 2.

Similar calculations are performed for a mixture of zeolite and carbon nanotubes. The obtained data can be found in Table 3.

As it can be seen from the tables, even a small amount of carbon nanoparticles significantly improve the bed-to-wall heat transfer coefficient for both and fluidized bed.

\section{Conclusions}

Fixed and bubbling fluidized bed conditions are considered in the paper. The model allows conducting a numerical study and describes the behaviour of heat transfer in the fixed and fluidized bed for a wide range of operational sceneries.

The proposed design concept allows significantly increase the heat transfer coefficient between adsorption bed and the surface of a heat exchanger as well as the bed conductance.

The use of a fluidized bed will help improve the coefficient of performance and cooling capacity of the chiller.

Scientific work was performed within the project No. 2018/29/B/ST8/00442, "Research on sorption processes intensification methods in modified construction of adsorbent beds" supported by National Science Center, Poland. The support is gratefully acknowledged. 
Table 1. Heat transfer coefficients for basic solids.

\begin{tabular}{|c|c|c|c|c|c|c|}
\hline \multicolumn{7}{|c|}{ Carbon nanotubes } \\
\hline & \multicolumn{2}{|c|}{$\mathrm{d}=50 \mu \mathrm{m}$} & \multicolumn{2}{|c|}{$\mathrm{d}=100 \mu \mathrm{m}$} & \multicolumn{2}{|c|}{$\mathrm{d}=150 \mu \mathrm{m}$} \\
\hline$v_{0}$ & $U_{f x}$ & $U_{f l}$ & $U_{f x}$ & $U_{f l}$ & $U_{f x}$ & $U_{f l}$ \\
\hline $\mathrm{m} \mathrm{s}^{-1}$ & \multicolumn{6}{|c|}{$\mathrm{W} \mathrm{m}{ }^{-2} \mathrm{~K}^{-1}$} \\
\hline 0.030 & 126.36 & 478.07 & 63.19 & 463.35 & 42.14 & 453.93 \\
\hline 0.100 & 126.45 & 554.02 & 63.28 & 526.12 & 42.22 & 509.43 \\
\hline 0.500 & 126.93 & 372.89 & 63.77 & 297.52 & 42.71 & 262.65 \\
\hline \multicolumn{7}{|c|}{ Silica gel } \\
\hline & \multicolumn{2}{|c|}{$\mathrm{d}=50 \mu \mathrm{m}$} & \multicolumn{2}{|c|}{$\mathrm{d}=100 \mu \mathrm{m}$} & \multicolumn{2}{|c|}{$\mathrm{d}=150 \mu \mathrm{m}$} \\
\hline$v_{0}$ & $U_{f x}$ & $U_{f l}$ & $U_{f x}$ & $U_{f l}$ & $U_{f x}$ & $U_{f l}$ \\
\hline $\mathrm{m} \mathrm{s}^{-1}$ & \multicolumn{6}{|c|}{$\mathrm{W} \mathrm{m^{-2 }} \mathrm{K}^{-1}$} \\
\hline 0.030 & 21.81 & 341.44 & 10.92 & 305.59 & 7.29 & 280.89 \\
\hline 0.100 & 21.89 & 377.06 & 11.01 & 327.29 & 7.38 & 294.37 \\
\hline 0.500 & 22.38 & 175.31 & 11.49 & 128.12 & 7.87 & 103.99 \\
\hline \multicolumn{7}{|c|}{ Zeolite } \\
\hline & \multicolumn{2}{|c|}{$\mathrm{d}=50 \mu \mathrm{m}$} & \multicolumn{2}{|c|}{$\mathrm{d}=100 \mu \mathrm{m}$} & \multicolumn{2}{|c|}{$\mathrm{d}=150 \mu \mathrm{m}$} \\
\hline$v_{0}$ & $U_{f x}$ & $U_{f l}$ & $U_{f x}$ & $U_{f l}$ & $U_{f x}$ & $U_{f l}$ \\
\hline $\mathrm{m} \mathrm{s}^{-1}$ & \multicolumn{6}{|c|}{$\mathrm{W} \mathrm{m}{ }^{-2} \mathrm{~K}^{-1}$} \\
\hline 0.030 & 13.69 & 280.18 & 6.87 & 243.09 & 4.59 & 219.05 \\
\hline 0.100 & 13.78 & 305.42 & 6.95 & 255.86 & 4.68 & 225.17 \\
\hline 0.500 & 14.26 & 131.53 & 7.44 & 92.35 & 5.16 & 73.53 \\
\hline
\end{tabular}

Table 2. Heat transfer coefficients for silica gel and carbon nanotubes particles.

\begin{tabular}{|c|c|c|c|c|c|c|}
\hline \multicolumn{7}{|c|}{ Silica gel $(90 \%)$ wt. and carbon nanotubes $10 \%$ (wt.) } \\
\hline & \multicolumn{2}{|c|}{$\mathrm{d}=50 \mu \mathrm{m}$} & \multicolumn{2}{|c|}{$\mathrm{d}=100 \mu \mathrm{m}$} & \multicolumn{2}{|c|}{$\mathrm{d}=150 \mu \mathrm{m}$} \\
\hline$v_{0}$ & $U_{f x}$ & $U_{f l}$ & $U_{f x}$ & $U_{f l}$ & $U_{f x}$ & $U_{f l}$ \\
\hline $\mathrm{m} \mathrm{s}^{-1}$ & \multicolumn{6}{|c|}{$\mathrm{W} \mathrm{m}^{-2} \mathrm{~K}^{-1}$} \\
\hline 0.030 & 55.41 & 580.99 & 27.72 & 539.33 & 18.49 & 509.95 \\
\hline 0.100 & 55.49 & 651.70 & 27.80 & 590.11 & 18.58 & 547.99 \\
\hline 0.500 & 55.98 & 336.42 & 28.29 & 258.72 & 19.06 & 217.34 \\
\hline \multicolumn{7}{|c|}{ Silica gel $(80 \%)$ wt. and carbon nanotubes $20 \%$ (wt.) } \\
\hline & \multicolumn{2}{|c|}{$\mathrm{d}=50 \mu \mathrm{m}$} & \multicolumn{2}{|c|}{$\mathrm{d}=100 \mu \mathrm{m}$} & \multicolumn{2}{|c|}{$\mathrm{d}=150 \mu \mathrm{m}$} \\
\hline$v_{0}$ & $U_{f x}$ & $U_{f l}$ & $U_{f x}$ & $U_{f l}$ & $U_{f x}$ & $U_{f l}$ \\
\hline $\mathrm{m} \mathrm{s}^{-1}$ & \multicolumn{6}{|c|}{$\mathrm{W} \mathrm{m} \mathrm{m}^{-2} \mathrm{~K}^{-1}$} \\
\hline 0.030 & 60.90 & 617.72 & 30.47 & 574.47 & 20.32 & 543.59 \\
\hline 0.100 & 60.99 & 693.68 & 30.55 & 629.50 & 20.41 & 585.16 \\
\hline 0.500 & 61.47 & 361.06 & 31.04 & 278.42 & 20.89 & 234.18 \\
\hline
\end{tabular}

Table 3. Heat transfer coefficients for zeolite and carbon nanotubes particles.

\begin{tabular}{|c|c|c|c|c|c|c|}
\hline \multicolumn{7}{|c|}{ Zeolite $(90 \%)$ wt. and carbon nanotubes $10 \%$ (wt.) } \\
\hline \multirow[b]{2}{*}{$v_{0}$} & \multicolumn{2}{|c|}{$\mathrm{d}=50 \mu \mathrm{m}$} & \multicolumn{2}{|c|}{$\mathrm{d}=100 \mu \mathrm{m}$} & \multicolumn{2}{|c|}{$\mathrm{d}=150 \mu \mathrm{m}$} \\
\hline & $U_{f x}$ & $U_{f l}$ & $U_{f x}$ & $U_{f l}$ & $U_{f x}$ & $U_{f l}$ \\
\hline $\mathrm{m} \mathrm{s}^{-1}$ & \multicolumn{6}{|c|}{$\mathrm{W} \mathrm{m}^{-2} \mathrm{~K}^{-1}$} \\
\hline 0.030 & 55.41 & 619.21 & 27.72 & 573.01 & 18.49 & 541.49 \\
\hline 0.100 & 55.49 & 693.03 & 27.80 & 625.14 & 18.58 & 579.94 \\
\hline 0.500 & 55.98 & 352.03 & 28.29 & 269.40 & 19.06 & 226.03 \\
\hline \multicolumn{7}{|c|}{ Zeolite (80\%) wt. and carbon nanotubes $20 \%$ (wt.) } \\
\hline & \multicolumn{2}{|c|}{$\mathrm{d}=50 \mu \mathrm{m}$} & \multicolumn{2}{|c|}{$\mathrm{d}=100 \mu \mathrm{m}$} & \multicolumn{2}{|c|}{$\mathrm{d}=150 \mu \mathrm{m}$} \\
\hline$v_{0}$ & $U_{f x}$ & $U_{f l}$ & $U_{f x}$ & $U_{f l}$ & $U_{f x}$ & $U_{f l}$ \\
\hline $\mathrm{m} \mathrm{s}^{-1}$ & \multicolumn{6}{|c|}{$\mathrm{W} \mathrm{m} \mathrm{m}^{-2} \mathrm{~K}^{-1}$} \\
\hline $\mathbf{0 . 0 3 0}$ & 60.90 & 651.35 & 30.47 & 604.17 & 20.32 & 571.34 \\
\hline 0.100 & 60.99 & 730.11 & 30.55 & 660.48 & 20.41 & 613.35 \\
\hline 0.500 & 61.47 & 374.99 & 31.04 & 288.01 & 20.89 & 241.94 \\
\hline
\end{tabular}




\section{References}

1. J. Krzywanski, K. Grabowska, M. Sosnowski, A. Żyłka, K. Sztekler, W. Kalawa, T. Wójcik, and W. Nowak, MATEC Web of Conferences 240, 05014 (2018)

2. J. Krzywanski, K. Grabowska, M. Sosnowski, A. Zylka, K. Sztekler, W. Kalawa, T. Wojcik, and W.

Nowak, Thermal Science 23, 1053 (2019)

3. K. Grabowska, M. Sosnowski, J. Krzywanski, K. Sztekler, W. Kalawa, A. Zylka, and W. Nowak, Journal of Thermal Science 27, 421 (2018)

4. K. Grabowska, M. Sosnowski, J. Krzywanski, K. Sztekler, W. Kalawa, A. Zylka, and W. Nowak, MATEC Web Conf. 240, 01010 (2018)

5. M. L. de Souza-Santos, Energy 120, 959 (2017)

6. J. Krzywanski, A. Żyłka, T. Czakiert, K. Kulicki, S. Jankowska, and W. Nowak, Powder Technology 316, 592 (2017)

7. J. Werther, Powder Technology 102, 15 (1999)

8. J. Krzywanski, M. Wesolowska, A. Blaszczuk, A. Majchrzak, M. Komorowski, and W. Nowak, Procedia Engineering 157, 66 (2016)

9. A. Błaszczuk and J. Krzywański, Archives of Thermodynamics 38, 91 (2017)

10. J. Krzywanski, H. Fan, Y. Feng, A. R. Shaikh, M. Fang, and Q. Wang, Energy Conversion and

Management 171, 1651 (2018)

11. W. Muskała, J. Krzywański, R. Rajczyk, M.

Cecerko, B. Kierzkowski, W. Nowak, and W. Gajewski, Rynek Energii 87, 97 (2010)

12. W. Muskała, J. Krzywański, R. Sekret, and W.

Nowak, Chemical and Process Engineering - Inzynieria Chemiczna i Procesowa 29, 473 (2008)

13. W. Muskała, J. Krzywański, T. Czakiert, and W. Nowak, Rynek Energii 172 (2011)

14. K. K. Win, W. Nowak, H. Matsuda, M. Hasatani, Z. Bis, J. Krzywanski, and W. Gajewski, JOURNAL OF CHEMICAL ENGINEERING OF JAPAN 28, 535 (1995)

15. J. Krzywanski, Entropy 21, 919 (2019)

16. J. Krzywański, M. Szyc, W. Nowak, and Z.

Kolenda, Technical Sciences / University of Warmia and Mazury in Olsztyn nr 19(4), (2016)

17. Q. Wang, X. Gao, J. Y. Xu, A. S. Maiga, and G. M. Chen, International Journal of Refrigeration 35, 694 (2012)

18. C.-H. Chen, G. Schmid, C.-T. Chan, Y.-C. Chiang, and S.-L. Chen, Applied Thermal Engineering 89, 229 (2015)

19. A. M. Hamed, Renewable Energy 30, 1913 (2005)

20. Z. Rogala, P. Kolasiński, and Z. Gnutek, Applied

Thermal Engineering 127, 950 (2017)

21. M. Z. I. Khan, K. C. A. Alam, B. B. Saha, A.

Akisawa, and T. Kashiwagi, Applied Thermal

Engineering 27, 1677 (2007)

22. M. Z. I. Khan, K. C. A. Alam, B. B. Saha, Y.

Hamamoto, A. Akisawa, and T. Kashiwagi, International Journal of Thermal Sciences 45, 511 (2006)
23. D. Kunii and O. Levenspiel, Fluidization

Engineering (Elsevier, 2013)

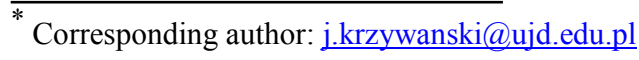

